\title{
THE INFLUENCE OF THE VARIETY OF SUGAR-CANE ON ITS INFESTATION BY DIATRAEA SACCHARALIS, AND THE OTHER FACTORS AFFECTING THE ABUNDANCE OF THE IIOTH BORER.
}

By 'G. N. Wоцсотт, Entomologist.

The insect doing most damage to sugar cane in Porto Rico is the moth stalk-borer, Diatraea saccharalis Fabr. Other insects such as white grubs (Lachnosterna vandinei Smyth, L. portoricensis Smyth and Strataegus titanus Fabr.) and root borers (Diaprepes spengleri Linn.) cause more severe and obvious injury in restricted localities, but the moth borer is abundant in cane from all parts of the Island, and its injury is none the less severe because it is less obvious. The injury is caused by the eaterpillar, which bores into the young shoots, killing the center and stopping the growth of that shoot, or bores into the stalks, making tunnels which sometimes stunt or kill the top of the cane stalk, but always retard the growth and cause a loss in weight, resulting in a loss of sugar. It has been found by comparative analyses of clean and infested cane "that, on the average, 900 pounds of available sugar is lost for each acre of cane harvested on the south side (of Porto Rico) due to the moth borer"'(1), and on the east coast of Porto Rico, the loss "exceeded 670 pounds of sugar per acre" $\left({ }^{2}\right)$. In Louisiana the loss has been estimated at slightly over 1,000 pounds per acre (1,061 lbs., 1,078 lbs. and 1,082 lbs.) $\left({ }^{3}\right)$.

The purpose of this paper is to point out what has been learned about the habits and abundance of the moth borer as affected by the methods of cane cultivation practised in Porto Rico, the varieties grown and, incidentally, by the rainfall. Whether the reduction in borer injury usually resulting from a change in method of cultivation or variety grown is of sufficient importance to justify its adoption, is a problem to be decided by each cane-grower for himself. All changes suggested are recommended solely from the standpoint of reducing borer injury and their adoption in actual field practice will depend upon many other considerations.

There are four stages in the life-cycle of the moth borer, of which the caterpillar is the one most familiar to everybody, as it is in this stage that all the injury is caused. The caterpillar is white or light- 
colored, often spotted with black, and when full grown about an inch long. The eaterpillar changes to a brown pupa or chrysalis in an enlarged tunnel in the cane stalk, from which a light yellow moth

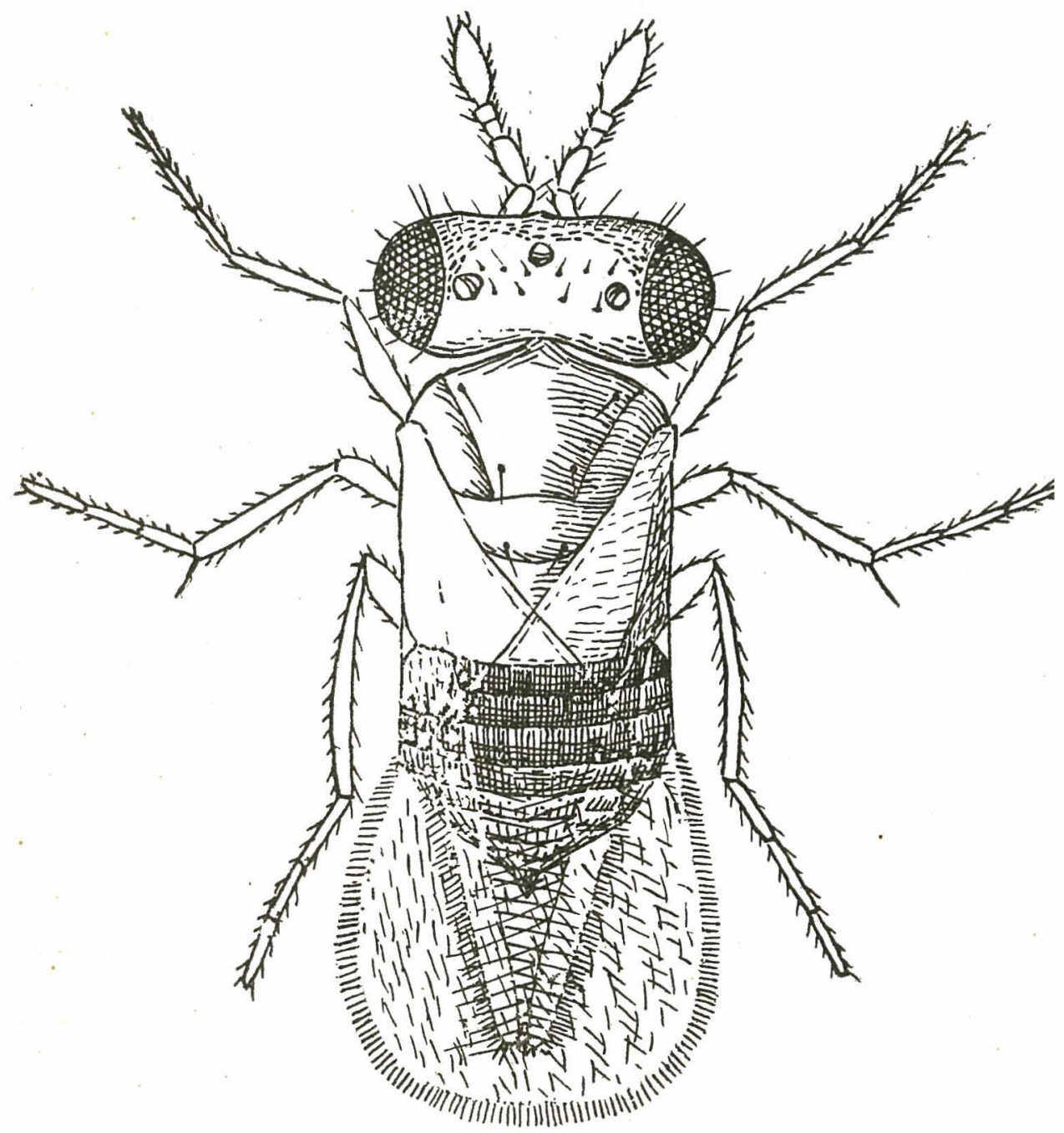

FIG. 8.-Trichogramma minutum Riley, the commonest parasite of the eggs of Diatraea saccharatis. Enlarged 170 times. (Original.)

emerges a week later. The moths are seldom seen in a cane field as they remain quiet during the day and the female deposits her eggs at night. The flat, creamy eggs occur in clusters of varying 
number, laid in rows and overlapping like shingles, on cane leaves. The young caterpillars chew small holes in the leaves or burrow in the midrib, but soon become large enough to burrow into the stalk. Under the mast favorable conditions, the whole life-cycle may be

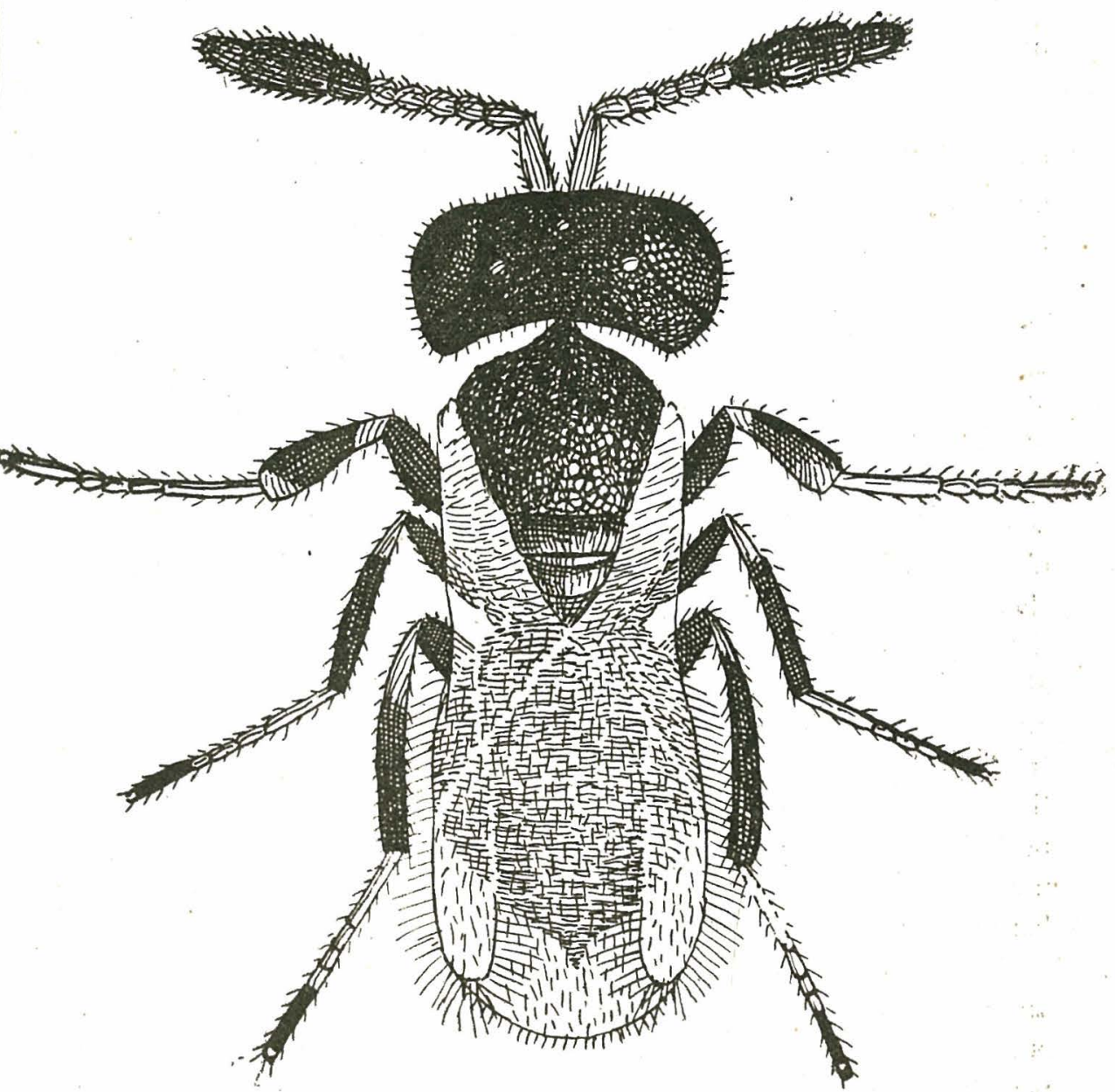

FIG. 9.-Prophanurus alecto Cwfd., a parasite of the eggs of Diatraea saccharalis. Enlarged 170 times. (Original.)

completed in twenty-five days, but ordinarily it takes a month or a little longer. Thus in cane which takes twelve months to mature there are the tunnels of at least ten generations of borers, and correspondingly more in older cane. 
During the grinding seasons of 1915 and 1916, nearly 50,000 stalks of sugar cane were inspected in all parts of Porto Rico, primarily to determine the abundance of injuries from the borer, and what factors of cultural methods or climate affected its abundance. The results showed that-

(1) In general, the per cent of infestation was inversely proportional to the rainfall; that is, an abundance of rain meant few borers and little rain meant many borers $\left({ }^{4}\right)$.

(2) "In 1915 the infestation by Diatraea was 100 per cent higher by localities in fields where the trash was burned and in 1916 it was 50 per cent highèr" than in fields where the trash had not been burned ( $\left.{ }^{1}\right)$.

The difference due to rainfall has not been satisfactorily explained, but that due to the burning or non-burning of the trash of the preceeding crop has been credited to its effect on a common egg parasite, Trichogramma minutum Riley, (Fig. 8.) of the borer. When a field of trash is burned, many of the adult borer moths and some of the caterpillars in the stalks on the ground or in the stubble will be destroyed, but practically all of the parasites-insignificant little wasps about the size of a pinhead-will be killed. When the young ratoon shoots come up, moths developing from undestroyed larvae in that field, or flying in from other fields of cane being cut, or from cut cane at loading stations, lay their eggs on the young cane leaves, and if all the parasites in that field have been destroyed by burning the trash, young borer caterpillars will develop from these eggs. But if the parasites are present in abundance, the female wasps will oviposit in some or most of the egg clusters and from these more wasp parasites will emerge to destroy succeeding generations of mothborer eggs.

The little wasps, Trichogramma minutum, are one thirty-fifth of an inch long, light yellow in color, except for pink eyes and a darkened base of the abdomen. The wings are transparent, lined and margined with fine hairs, those of the long narrow underwings being very long. Quite recently another egg parasite of Diatraea has been found in Porto Rico, Prophanurus alecto Crawford, identified by Mr. A. B. Gaban, (Fig. 9.) of about the same size as Trichogramma, but all black except for some segments of the antennae and and legs, which are dark yellow. The former parasite is much more common, and bas a wide distribution, being found in many tropical and subtropical countries, while the latter, first described from 
Demerara, has been found in addition only in some of the Lesser Antilles.

The accompanying illustrations were drawn from live wasps as they appeared under a compound microscope, and are magnified one hundred and seventy times. Because of their minute size, the wasps will never be observed in the field, except possibly when just emerging from a Diatraea egg cluster, or when ovipositing in one, but the effects of their presence in abundance will be apparent in lessened damage to the sugar cane by the borers.

However, the burning or non-burning of trash in some sections of the Island, especially along the south coast between Fortuna and Arroyo, seemed to have little or no effect on the moth-borer. Many field men, who were present while counts of the borer injuries in their cane were being made, have suggested that the variety of cane had something to do with its infestation by the borer. The following is the average infestation of the various varieties of sugar cane:

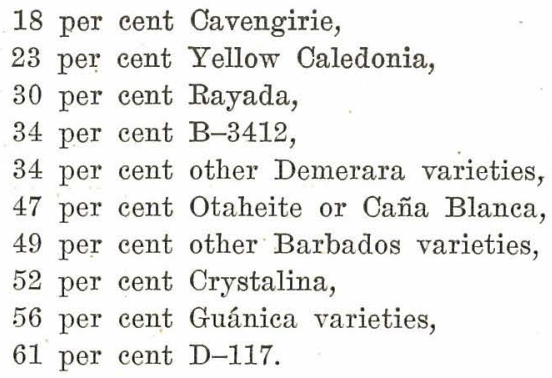

But this does not tell the whole story. The distribution of the different varieties is very uneven in various parts of Porto Rico, some being grown only in the dry sections and others only in the wet. As the percentage of infestation is affected by the amount of rainfall and by the burning or non-burning of trash, the separation of the data under these headings' gives a fairer standard of comparison. (See page 26.)

Also, many, if not most, of the cane fields in Porto Rico contain a mixture of two or more varieties. When more than two varieties were present, the record was discarded as useless in preparing the table, but when only two are present, half credit is given for that examination to each of the two varieties. The average of the mixed cane often differed considerably from that of the average of the variety, but usually so as to show a more sharp contrast between the environments. This is the case in the figures for Crystalina in 


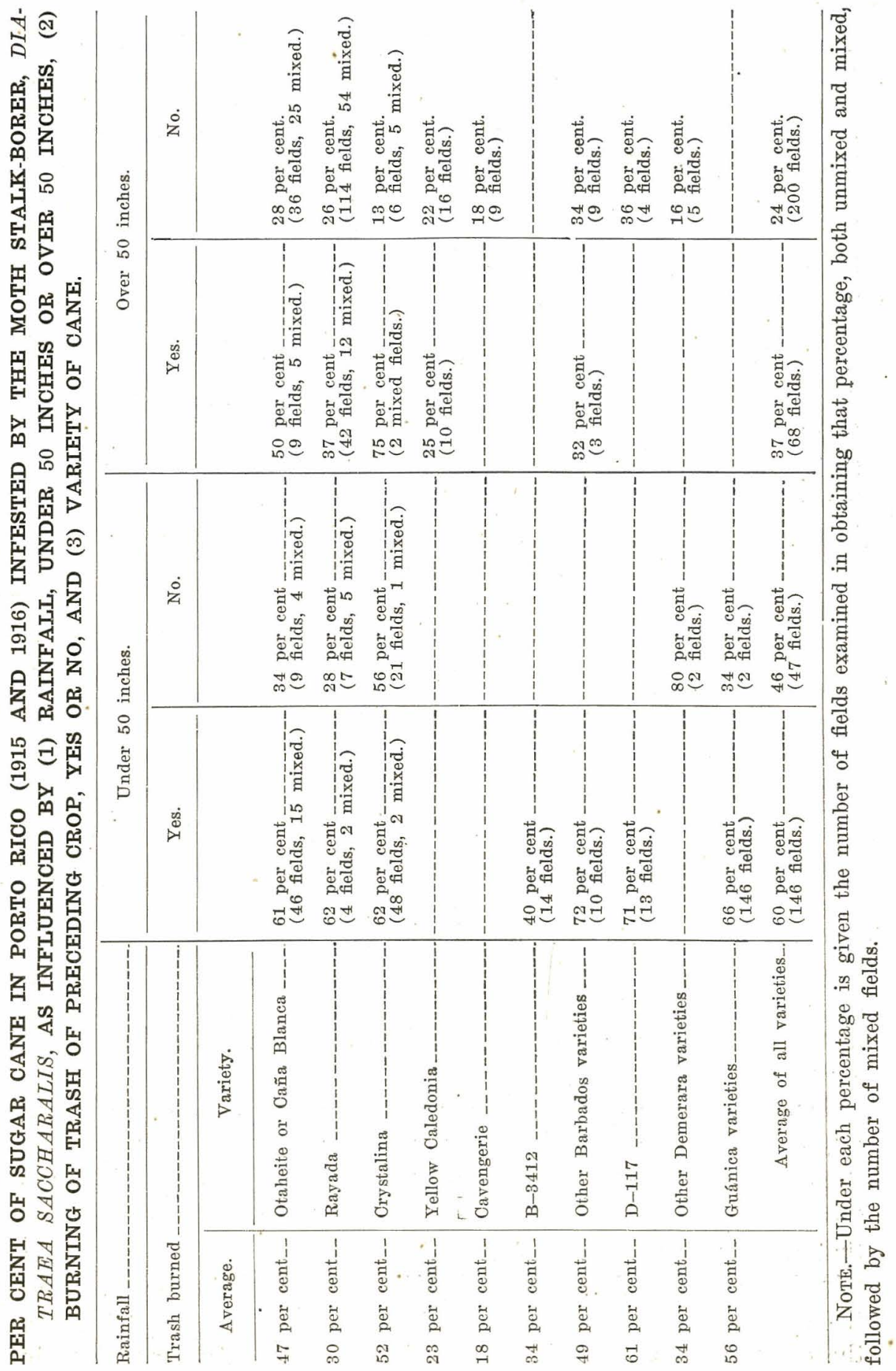


the fields of abundant rainfall, but not too much weight should be given these records when over half are from mixed cane.

Also, little weight should be attached to records obtained by the examination of only a few fields (and those from only one field under a heading have purposely been omitted), but records from more than ten fields, when less than half are of mixed cane, may be considered as being a true record of average conditions for that variety and environment. Unfortunately the data is lacking for making comparisons of many varieties under all conditions and is insufficient for reaching definite and final conclusions on many points. But the considerable amount of data on some varieties and under some environments make it possible to state that. (at least in 1915 and 1916) in Porto Rico-

(1) Crystalina in the dry sections and Yellow Caledonia in the moist sections are only slightly affected by the burning or non-burning of the trash, but Otaheite and Rayada in all comparable sections of the Island are nearly (or over) twice as heavily infested where the trash has been burned, and, if much confidence may be placed in an average of two observations, this is also true of the Guánica varieties.

(2) The canes most commonly grown in Porto Rico, Otaheite, Rayada and Cristalina, are equally infested in trash-burned fields of the dry sections of the Island. B-3412 has an apparently lower infestation, but as this variety has a thin stalk, probably has as many borers per acre or per ton as the other common varieties, but compares most favorably with D-117 and the other Barbados, Demerara and Guánica seedling varieties.

(3) Rayada is somewhat less attacked by borer under other conditions than is Otaheite.

(4) Yellow Caledonia and Cavengirie, despite the long season (18 months) necessary for them to reach maturity, have the lowest infestation of any canes grown in the moister sections of the Island. In this connection it should be noted that B-3412, which has the lowest infestation per stalk in the dry section of the Island, is also a long-season cane.

The characteristic of these varieties which is responsible for the difference in borer infestation is not at once apparent. Yellow Caledonia, Cavengirie and B-3412 are long-season canes with low sucrose content until they mature, while Crystalina has considerable sugar even when immature, and this checks up fairly well with the 
data at hand. But D-117, with only a slightly shorter season than B-3412, is nearly twice as heavily infested. The hardness of rind, or high percentage of fiber and difficulty of milling, which is also characteristic of the canes with low borer infestation, would seem to be more the sort of thing that would affect an insect that chews and bores into their stalks, but Otaheite, the easiest milling cane, does not have the highest borer infestation. B-3412 and D-117 have very nearly the same amount of fiber. Although the borer may live and complete its development in the older and harder portion of the cane, the majority of the caterpillars live in the young shoots or in the younger growing top of the older cane, which is soft and comparatively easily bored in all varieties. It is quite possible that the varying degrees of the acidity or possible esters of the cane juice, as affected by variety and rainfall, in these growing portions of the cane, is the determining factor favoring or retarding its development, but no data is available for judging of this.

Whatever may be the cause of the difference in infestation of the varieties, its practical importance to the cane-grower is that when it is practicable to grow Yellow Caledonia and Cavengirie, and possibly B-3412, borer infestation is automatically reduced.

Mr. R. A. Veve, of the Experiment Station of the Fajardo Sugar Company, in 1919-20 and 1920-21, made counts of Diatraea infestation in a considerable number of varieties of cane grown in $\mathrm{Ha}$ ciendas Santa Rita, Santa María and San Pedro, where the rainfall was abundant, and usually where the trash had not been burned. The averages of all his counts of some varieties is as follows:

D 116, 32 per cent infested (2 counts).

Rayada, 31 per cent infested ( 8 counts).

Otaheite, 30 per cent infested ( 2 counts).

D 109, 27 per cent infested (3 counts).

D 117, 21 per cent infested (3 counts).

D 433, 21 per cent infested (11 counts.)

Y. C., 16 per cent infested (4 counts).

Cavengirie, 8 per cent infested (1 count).

There is one point in the habits of the moth borer that renders it possible to somewhat reduce its numbers in young plant cane. The moths can not emerge from their pupal stage if the cane is buried under the soil, but have no difficulty in emerging from discarded seed left on the banks or in the callejones where the seed is recut and reselected for planting. All seed containing borer caterpillars, or showing their injury, SHOULD BE PLANTED, as this does not cause 
the young shoots to be infested, and ordinarily germination is just as good from such seed $\left({ }^{1}\right)$, and sometimes better, because the borer has stunted growth and caused the production of more eyes. Or if such seed is discarded, it should be BURIED. Burning is not effective as the seed will not burn while green and if delayed until dry enough to burn, most of the moths will have emerged. By the proper care of infested seed, either planting or burying it, one source of infestation of young plant cane is eliminated.

But the prevention of the emergence of the moths from infested seed may have no apparent effect, as there are other sources of infection. The grinding of the cane at the mill destroys large numbers of borers, probably the majority present in the cane, but from the beginning of cutting until the cane is ground-until ALL of it is ground-it constitutes a constant menace and source of infection for all nearby fields.

Usually young plant cane has other fields of cane in various stages of growth on from one to all sides of it and adult female moths will fly in from these adjacent fields, especially when they are disturbed when the cane is being cut. The only way of obviating this would be to begin harvesting at one end of a property, preferably beginning to the windward, or in the fields farthest away from the mill and cutting towards the mill, and cut all cane in regular sequence until the other end is reached, planting no cane until all the cane from surrounding fields is harvested.

Often when cane is being cut, the poorest stalks will be left in the field and not taken to the mill to be ground. The stalks may be poor because of disease, or because the rats have chewed them, but the usual reason why they are poor and not worth harvesting is because they have been injured by the borer. The adult moths have often not emerged from this cane at the time it is cut, and if it is left in the field they will be able to lay their eggs on the young ratoon shoots. Burning the trash does not kill all the borer larvae in stalks on the ground, although it does kill some, and is largely ineffective in its immediate consequences and positively harmful eventually in borer control. All cane should be sent to the mill to be ground, as this is the only sure way of destroying the borers and other harmful insects in it.

Occassionally borers are found in stubble after the cane has been cut, but this is comparatively rare as the borers usually live in the 
younger parts of the cane stalk, and practically never occurs if the stalks are cut close to, or slightly below, the surface of the ground.

There is one other important source of infection and that is the cut cane deposited at loading stations, or in the cars here or en route to the mill, or in the batey at the mill. On the leaves of the young plants of plant or ratoon cane adjacent to a loading station or the railroad sidings where loaded cane cars are stored, egg clusters of the borer will usually be found in abundance, due to the moths which have emerged from the cane before it reached the mill and flown to the nearest cane field. There is no way of avoiding this source of infestation after the loading station is located and built, and ordinarily there is every other reason in favor of having it as near as possible to the fields where the cane is cut. When the mill, however, is located outside the cane-growing district (as Guánica Centrale and Central Aguirre), moths emerging from the cane in the cars stored in the batey ordinarily perish before they are able to fly to the nearest cane field and lay their eggs. It is sometimes possible to have the fields around the mill or along the switches where the loaded cane cars are temporarily stored, in pasture rather than in cane. This is by no means a minor source of infection, as an example will show. Suppose stalks of cane average four pounds each (which is low for Yellow Caledonia, but somewhat high for most other varieties), then one ton contains 500 stalks, of which, if fifty per cent are infested with the borer-which is a fair average for Porto Rico-and one-tenth contain live borers (there being about ten generations of the borer in twelve months, the minimum growing period for cane), then there are twenty-five live borers in one ton of cane. Every day one of these borers will be ready to emerge as an adult moth, so that for each day that a loaded twenty ton cane car remains near a cane field, ten male and ten female moths will emerge and fly into the adjacent fields. As the cane at a loading station is constantly renewed, there is a constant stream of moths emerging from it and flying to the nearby cane, even though no cane is there for an extended period.

If the little wasp egg parasites (Trichogramma minutum) are present in abundance in a field, they will destroy some of the borer egg clusters resulting from the moths reaching the field from sources of infection which cannot be eliminated, but this again emphasises the importance of not burning the trash. Burning the trash destroys 
most of these beneficial little insects, as they can not fly far and escape the destruction of a cane fire.

Non-burning of trash, to favor the egg parasites, growing of varieties resistance to borer attack, such as Yellow Caledonia, Cavengirie, and B-3412, and care in burying infested seed and cleaning up infested cane and sending it to the mill as soon as possible, will reduce injury by the moth stalk-borer of sugar cane, Diatraea saccharalis.

\section{LITERATURE CITED.}

1. Wiolcotт, G. N. "Report of the Entomologist." 5th Rpt. Bd. Comm. of Agr. P. R., 1917, pp. 80-85.

2. VAN Dine, D. L. "Damage to Sugar-Cane Juice by the Moth Stalk-Borer, Diatraea saccharalis Fabr." Cir. No. 1, Exp. Sta-» tion Sugar Growers Assn. P. R., Río Piedras, P. R., Feb. 1912.

3. Holloway, T. E., and Loftin, U. C. "The Sugar-cane Moth Borer,' U. S. Dept. Agr. Bulletin No. 746, Washington, D. C., April 18, 1919.

4. WoLсотт, G. N., "The Influence of Rainfall and the Burning of Trash on the Abundance of Diatraea saccharalis." Circular No. 7, Bd. Comm. Agric. P. R., Insular Experiment Station, Río Piedras, Porto Rico, 1915. 